\title{
Beleza Física e Trabalho Imaterial: do Politicamente Correto à Rentabilização
}

Physical Beauty and Immaterial Labor: from Political Correctness to Monetization

La Belleza Física y Trabajo Inmaterial: hacer Políticamente Correcto a Monetización

Carmem Lígia lochins Grisci, Estéfani Sandmann de Deus, Sabrina Rech, Maura Ferreira Rodrigues \& Pedro Henrique de Gois

Universidade Federal do

Rio Grande do Sul

http://dx.doi.org/10.1590/1982-370302282013 
Resumo: o presente estudo resulta de uma pesquisa qualitativa exploratória que objetivou verificar e analisar como a beleza física é vista, e como sua presença/ausência afeta os trabalhadores no cotidiano do trabalho imaterial bancário. Para tanto, realizou-se 12 grupos focais que totalizaram 265 participantes - 134 mulheres e 131 homens - provenientes de uma mesma instituição bancária do setor público. A análise dos resultados seguiu as orientações de Minayo e encontrou respaldo à luz da literatura pertinente que aponta o controle-estimulação, a responsabilização pela conquista e manutenção da beleza física e sua consequente naturalização. Os resultados permitem compreender a beleza física como investimento na carreira, instrumento da gestão gerencialista, definidora da visibilidade/invisibilidade dos corpos, e fonte de sofrimento psíquico. Nesse sentido, a gestão gerencialista se faz notar ao tornar a beleza física rentável. Suas consequências humanas como rejeição, incitação à adesão, impedimentos à ascensão na carreira e sofrimento carecem de divulgação, embora componham o conjunto de elementos relativos à produção de estilos de vida na sociedade líquido-moderna.

Palavras-chave: Trabalho. Corpo. Aparência Física. Estilo de Vida.

Abstract: This study is a result of an exploratory qualitative study aimed at verifying and analyzing how physical beauty is perceived and how its presence/absence affects the daily immaterial labor of workers in banking. Therefore, 12 groups were formed with 265 participants - 134 women and 131 men-from the same bank in the public sector. This analysis followed the guidelines of Minayo and was supported by relevant literature, highlighting stimulus control, achievement and maintenance of physical beauty, and its consequent naturalization. The results allow us to understand physical beauty as a way of climbing the career ladder, responsible for managerialism, defining the visibility/invisibility of bodies, and a cause of psychological distress. Therefore, the managerialist management is considered to benefit physical appearance. Its human consequences include rejection and adhesion, and it can also act as an obstacle to career progression. It lacks disclosure, although it composes elements associated with lifestyle production (Deleuze, 1998) in the "liquid modern" society.

Keywods: Labour. Body. Physical Appearance. Lifestyle

Resumen: Este estudio resulta de una pesquisa exploratoria cualitativa que objetivó verificar y analizar como La belleza física es vista, y como su presencia/ausencia afecta a los trabajadores en el cotidiano del trabajo bancario inmaterial. Se plantearon 12 grupos de enfoque que totalizaron 265 participantes - 134 mujeres y 131 hombres - provenientes de una misma institución bancaria del sector público. El análisis de los resultados siguió las directrices de Minayo con respaldo de la literatura relevante apuntando el control-estimulación, responsable por el logro y mantenimiento de la belleza física y su consecuente naturalización. Los resultados permiten entender la belleza física como una inversión en la carrera, instrumento de gestión empresarial, definiendo la visibilidad/invisibilidad de los cuerpos y fuente de distrés psicológico. En consecuencia, una gestión empresarial se hace notar si se torna una belleza física rentable. Sus consecuencias humanas como rechazo, incitación a la adhesión, impedimentos para elevarse en la carrera que carece de la divulgación, así como componer el conjunto de elementos relativos a la producción de los estilos de vida en la sociedad moderna líquida.

Palabras clave: Trabajo. Cuerpo. Apariencia Fisica. Estilo de Vida 


\section{Introdução}

A beleza física tem sido associada a situações de trabalho, o que pode ser constatado em manchetes recentes que apontam sua importância em alguns setores de trabalho. "Beleza no trabalho: novos estudos revelam que a aparência é um dos principais segredos do sucesso - e não há nada de errado em usá-la" (Marques, 2011, pp. 92-99); "Beleza física pode trazer vantagem para carreira" (Tozzi, 2012, pp. 1-2); "A vitória sobre o espelho" (Veja, 1995, pp. 70-79); "Candidatos à vaga de emprego em Porto Alegre ganham trato no visual'" $(G 1,2013)$.

Na contramão das políticas de inclusão, tais manchetes proliferam e ilustram um dos apelos que sofrem os indivíduos na sociedade líquido-moderna compreendida como aquela em que a "vida líquida, (...) assim como a sociedade líquido-moderna, não pode manter a forma ou permanecer em seu curso por muito tempo" (Bauman, 2007, p. 7).

1 De acordo com a Associação Brasileira da Indústria de Higiene Pessoal, Perfumaria e Cosméticos (Abihpec) (2013), os fabricantes de produtos de higiene e beleza registraram, no primeiro semestre de 2012, faturamento de

$R \$ 15,4$ bilhões, o que corresponde a um crescimento real (descontada a inflação) de 10,3\% sobre o mesmo período em 2011.

2 Segundo informações divulgadas pela SBCP

(Target, 2013), as cirurgias cresceram $129,9 \%$ no

Brasil entre os anos de 2009 e 2012, colocando o Brasil como segundo país no ranking mundial de cirurgias plásticas, sendo as mais procuradas a

lipoaspiração, o aumento de mamas, abdominoplastia, blefaroplastia (cirurgia da pálpebra) e redução de mamas.
Afirmativas, as manchetes condizentes com a sociedade líquido-moderna levam a crer que, na perspectiva da gestão de si (Gaulejac, 2007), caberia aos indivíduos agir no sentido de corresponder às demandas relativas à beleza física que se vinculam à imaterialização do trabalho (Grisci, 2008; Gorz, 2005; Lazzarato \& Negri, 2001).

Veiculadas em jornais e revistas, de ampla circulação e alcance, as manchetes estimulam indagações, ainda mais se associadas às divulgações realizadas pela Associação Brasileira da Indústria de Higiene Pessoal, Perfumaria e Cosméticos (ABIHPEC) ${ }^{1}$ e pela Sociedade Brasileira de Cirurgia Plástica (SBCP) ${ }^{2}$ que indicam elevação no consumo de produtos e procedimentos de embelezamento; e à literatura relativa à temática da produção de estilos de vida ou modos de existência (Deleuze, 1998) decorrentes das demandas do trabalho imaterial (Gorz, 2005; Lazzarato \& Negri, 2001).

Se o poder disciplinar, conforme analisado por Foucault (1996), objetiva tornar os corpos úteis, dóceis, produtivos, portanto em condições para o exercício do trabalho material exigente da força física e submissão aos movimentos repetitivos; aos olhos da gestão de si, correspondente ao trabalho imaterial, qual corpo acompanharia a mobilização da psique pelo poder gerencialista (Gaulejac, 2007)? No contexto de trabalho imaterial, seria a beleza física um instrumento da gestão? Que consequências teriam a presença ou a ausência da beleza física frente às demandas do trabalho imaterial? Como os corpos dos trabalhadores estão sendo produzidos no sentido de atenderem às atuais exigências do trabalho imaterial?

O trabalho bancário tem se mostrado campo profícuo aos estudos da imaterialização do trabalho. Nele se observa uma reconfiguração dos postos de trabalho que vem a privilegiar a chamada linha de frente ou aquelas atividades desenvolvidas em contato direto com a clientela, o que justifica apresentar a seguinte questão de pesquisa como relevante: que relações se estabelecem entre o trabalho imaterial bancário e a beleza física? A fim de respondê-la desenvolveu-se uma pesquisa qualitativa exploratória (Vergara, 2000) que objetivou verificar e analisar como a beleza física é vista, e como sua presença/ ausência afeta os trabalhadores no cotidiano do trabalho bancário.

A esta introdução, segue-se a revisão da literatura que privilegia os tópicos beleza física (Foucault, 1996; Sant' Anna, 2001) e trabalho imaterial (Gorz, 2005; Lazzarato \& Negri, 2001) tomando-os como elementos da produção de estilos de vida ou modos de existência (Deleuze, 1998) na sociedade líquido-moderna (Bauman, 2007). Na sequência, encontrar-se-ão os procedimentos metodológicos realizados, e a apresentação e análise dos resultados que se referem à beleza física como investimento na carreira, instrumento da gestão gerencialista, definidora da visibilidade/ invisibilidade dos corpos, e fonte de sofrimento. Por fim, as considerações finais acerca do estudo. 


\section{Trabalho Imaterial e Beleza Física}

Por trabalho imaterial compreendem-se as atividades corporais, intelectuais, criativas, afetivas e comunicativas mobilizadas pelos trabalhadores em termos de engenhosidade, gerenciamento de informação, tomada de iniciativa, investimento pessoal na tarefa e nas relações, antecipação e resolução de problemas. Elas fomentam uma nova relação produção-consumo que visa fazer emergir sentimentos de confiança, segurança e conforto por parte dos consumidores, e passa a ser considerada indispensável à produção e à competitividade das empresas (Gorz, 2005; Lazzarato \& Negri, 2001). O setor bancário, por onde circula o gestor de si, um dos novos personagens da imaterialização do trabalho, bem ilustra essa questão. Esse personagem concentra em si o que é demandado do coletivo dos trabalhadores, e indica que a dimensão micropolítica da produção capitalista alcançou a vida cotidiana e a produção da subjetividade "numa escala sem precedentes" (Pelbart, 2000, p. 37). São, portanto, seus estilos de vida - ilustrados na trajetória de engajamento, mobilização e disponibilidade total à lógica organizacional condizente com o trabalho imaterial - que se vêm indissociados da mercadoria, uma vez que o valor do dinheiro não mais se limita ao tempo de trabalho, alcançando também o tempo da existência (Foucault, 1996; Gaulejac, 2007; Grisci, 2008).

Na perspectiva do sequestro da subjetividade (Faria \& Meneghetti, 2007) - que toma o pensamento, a sensibilidade, a sociabilidadee os afetos dos sujeitos (Pelbart, 2003), inclusive sua capacidade de sedução - o trabalho imaterial distancia-se do trabalho material, e novas formas de poder que o caracterizam se fazem notar no corpo dos trabalhadores. Por meio de técnicas e instrumentos disciplinadores que levam à repetição e ao compasso de movimentos estabelecidos de antemão, o trabalho imaterial faz notar um corpo treinado em prol da produção (Foucault, 1996). Por meio da sedução e da "'não prescrição" normalizadora" (Gaulejac, 2007, p. 91), indutora de hábitos e comportamentos que levam à mobilidade e desenvoltura, o trabalho imaterial faz notar a beleza física que reflete aos olhos de outrem a imagem institucional (Grisci, 2008).

Recolocado em evidência o contexto de trabalho imaterial, o corpo ilustra o que Lipovetsky (1983) chama de investimento narcísico com seus rituais de controle e manutenção para o bem-estar pessoal e para o reconhecimento profissional, numa evidente relação entre corpo e prestígio que explicita os estilos de vida ou modos de existência (Deleuze, 1998), originados de dispositivos denominados controle-estimulação: "'Consuma!', 'Acesse!', 'Coma!', 'Cuide-se!'" (Mansano, 2009, p. 75). Condizentes com a gestão de si, eles podem ser tomados como "(...) um novo tipo de socialização 'racional' do sujeito (...) através do imperativo sedutor que quer que o indivíduo se informe, se administre a si próprio, preveja, se recicle, se subordine à regra da entrevista e do teste" (Lipovetsky, 1983, p.103).

Demandado a moldar, manter e colocar em evidência um corpo acolhedor do padrão de beleza vigente, ao gestor de si caberiam algumas ações. Eliminar o excesso de peso associado à indolência para o trabalho (Sant'Anna, 2001). Eliminar as marcas da passagem do tempo reciclando-se em uma juventude sem fim (Lipovetsky, 1983). Retrair-se à lógica do aqui e agora a vigorar na sociedade líquido-moderna imperativa da vida líquida "manter a forma ou permanecer em seu curso por muito tempo" (Bauman, 2007 , p. 7). Revelar por meio de investimentos em procedimentos estéticos e cirúrgicos, e treinos em academias, que "só é feio, fora de forma, flácido, enrugado e envelhecido quem quer, quem não se ama, não se cuida, não se pavoneia" (Couto, 2007, p. 42).

$\mathrm{Na}$ impossibilidade de resposta satisfatória ao teste, restar-Ihe-ia arcar com a pecha de insuficiente à hipersolicitação do corpo e da mente na hegemonia do trabalho imaterial, em que pese à observação de Sant'Anna:

A multiplicação de imagens sobre corpos saudáveis e sempre belos é bem mais rápida do que a produção real de saúde e beleza no cotidiano. A corrida 
rumo à juventude é hoje uma maratona que alcança jovens e idosos de diversas classes sociais, mas estes não conseguem ver o pódio, porque se trata de uma corrida infinita. Ignoram quem compete com quem, talvez porque a principal competição se passe dentro de cada um, entre o corpo que se é e o ideal de boa forma com que se sonha (2001, p. 88).

O atual culto ao corpo ressalta um individualismo perverso que torna cada indivíduo o único responsável pela forma física que possui (Miskolci, 2006). Consequentemente, a forma física de cada um estaria diretamente ligada à capacidade individual de autocontrole ou gestão de si, uma característica amplamente utilizada pela gestão como fator de sucesso profissional. Além disso, a atenção crescente ao corpo também vem demonstrando que o

culto ao corpo se tornou um estilo de vida, mas de uma vida tecnocientífica. A promessa fascinante de um ganho suplementar de saúde, juventude e beleza conquistou um espaço inédito nos meios científicos e artísticos, na mídia, em todas as esferas do nosso cotidiano (Couto, 2007, p.42).

Nesse sentido, há de se considerar, da perspectiva do trabalho imaterial, a possibilidade de tomar a beleza física como instrumento da gestão. Produzida culturalmente, a beleza física já indica certo jogo de poder em torno do verdadeiro. Nesse sentido, e não por acaso, o horror à gordura é comum. Atualmente estigma da indolência, a gordura é vista como incapacitante para o trabalho (Miskolci, 2006). Trata-se, portanto, especificamente de apontar a beleza física e não a beleza da coragem, por exemplo, no sentido de tomá-la aliada a outros quesitos relativos ao trabalho imaterial. Ou seja, focar os processos de subjetivação do corpo via gestão que promulga estratégias que constroem o olhar do que é a beleza física produtiva para o trabalho imaterial. Desse modo, distancia-se da lógica da percepção da beleza física por si e aproxima-se da percepção da beleza física como um dos efeitos dos atuais modos de trabalhar. Em relação à profissão de modelos, por exemplo, Goldenberg (2005) lembra Bourdieu ao afirmar que, a partir de seu corpo, sua aparência, sua beleza, ganharam um "nome".

Nesse sentido, cada um e todos são solicitados a construir o seu corpo, conservar a forma, a beleza, a fim de aniquilar os sinais de envelhecimento ou fragilidade, a ostentar a identidade do indivíduo, seja pelos sinais de beleza, seja pelos sinais de feiura (Paiva, 2007, p. 45).

Estudos de Hamermesh e Biddle (1994) indicaram a relevância da questão da aparência e beleza física nas relações de trabalho ao examinarem o impacto da beleza física sobre o salário nos Estados Unidos e Canadá. Verificaram que pessoas com beleza física considerada abaixo da média apresentam salários menores a taxas de 5\% a 10\% em relação às pessoas consideradas com beleza física acima da média, porém em uma taxa menor em relação às penalidades. Estudo de Grisci (2008), realizado em instituição bancária portuguesa de grande porte, possibilitou verificar, entre outros, a adoção da gestão da imagem que afeta os indivíduos em sua intimidade, no desejo de estar bem perante os outros, de vestir-se e conduzir-se com elegância, e, mais do que tudo, no desejo de não se envergonhar. A gestão da imagem resultaria uma padronização de modelos e cores nos modos de vestir, de se enfeitar, de pentear os cabelos, gesticular e posicionar o corpo de modo discreto e elegante. Trata-se de um modo de disciplina que resulta corpos padronizados, e subjetividades controladas (Miskolci, 2006).

Em contexto de trabalho imaterial que faz surgir o personagem gestor de si, e

Sob a lógica do consumo são deflagrados novos hábitos e comportamentos, onde cada um passa a ser responsável pelo gerenciamento da aparência e dinâmica física e mental, comprometido com fluxos, velocidades e imediatismos, visando resultados praticamente instantâneos. Sob o peso dessa responsabilidade cada um passa a ser avaliado, exaltado, 
julgado, acusado e, às vezes, condenado, pelo corpo e pela saúde que têm (Couto, 2007, p.53).

A beleza física, tomada à luz do conceito de trabalho imaterial, instiga a pensar a propensão da gestão em torná-la produtiva, rentável e fonte de competitividade entre as empresas. A relevância de sua problematização reside no

(...) paradoxo que não cessa de crescer: quanto mais o ego e o corpo de cada um são alvos de coações, explorações comerciais e forçados a ampliar seus recordes de consumo e rentabilidade, sob a ameaça de serem confundidos com dejeto, mais eles ficam carentes de reconhecimento, de cuidados e de afeto (Sant'Anna, 2001, 119).

A seguir, apresentar-se-ão os procedimentos metodológicos desenvolvidos no presente estudo.

\section{Procedimentos Metodológicos}

Cabe lembrar que o presente estudo desenvolveu-se a partir da seguinte questão de pesquisa: que relações se estabelecem entre trabalho imaterial bancário ebeleza física? A fim de respondê-la, desenvolveu-se uma pesquisa exploratória, de cunho qualitativo, que contou com a participação livre e consentida de 134 mulheres e 131 homens provenientes de uma mesma instituição bancária do setor público. Dos 265 participantes, com idade média de 40 anos, em torno de $50 \%$ são casados e os demais solteiros ou divorciados. Compartilhando por vários anos uma mesma história institucional, alguns por mais de duas décadas, no momento da pesquisa, eles distribuíam-se em cargos de analista, gerente executivo, auditor e superintendente com atuação concentrada no que denominam "Diretoria Geral" do banco, percebendo entre quatro e dez salários mínimos fixos. Divididos em doze turmas sucessivas de aproximadamente 22 participantes de ambos os sexos e cargos diversos, todos realizavam um curso de Especialização em Gestão Bancária com carga horária total distribuída em torno de 24 meses.
Considerado técnica pertinente ao presente estudo, o grupo focal é compreendido como "uma entrevista em grupo, na qual a interação configura-se como parte integrante do método" (Backes, Colomé, Erdmann e Lunardi, 2011, p.438), e legitimado em relação à pesquisa qualitativa em sua busca de sentidos, angústias, ansiedades e sofrimentos dos sujeitos, e da valorização do contexto em que se encontram inseridos (Turato, 2005).

Para a coleta de dados, realizaram-se 12 grupos focais correspondentes a cada uma das doze turmas integrantes do curso de Especialização. Optou-se pela técnica de grupo focal dada a disponibilidade rara de reunir tantos participantes de uma única instituição bancária para discutir a questão da beleza física no seu cotidiano de trabalho. Desse modo, os 12 grupos focais, gravados em áudio para posterior transcrição do conteúdo, somaram 679 minutos de gravação, com duração aproximada de 60 minutos cada um. Deles resultaram 160 páginas de transcrição literal das falas, formatadas em espaço simples que compuseram o corpo de análise. Todos os grupos focais tiveram a presença da mesma e única coordenadora e de mesma e única observadora, e partiram do seguinte estímulo: a beleza física no cotidiano do trabalho bancário vivenciado na especificidade da instituição a qual pertenciam. Os trechos retirados dos grupos focais são apresentados seguindo o seguinte padrão de citação: gênero, a indicação do grupo focal correspondente e o número da página na transcrição (por exemplo: M, GF 11, p. 14).

Em termos de operacionalização dos conceitos, inicialmente foi necessário diferenciar aparência física de beleza física, o que se mostrou tarefa árdua dada à aproximação que guardam entre si. Assim, para os propósitos do presente estudo, do conjunto de manifestações dos participantes, associou-se a aparência física, em especial à higiene e à vestimenta, revelando esforços impetrados pelos indivíduos no sentido de não parecerem desleixados e tornarem-se mais agradáveis ao olhar de outros. E a beleza física associou-se àquilo que, relativo ao físico de alguém, aos olhos de outrem é considerado belo, podendo 
inclusive ser resultado de intervenções ocorridas no sentido de propiciar mais beleza. Além disso, a beleza física distancia-se, também, do que se poderia denominar beleza interior ou beleza de caráter, por exemplo.

Cabe ressaltar que o grupo focal possibilitou aos participantes compartilharem lembranças, observações e experiências próprias relativas ao tema. Na medida em que algo era contado por uns e escutado por outros, legitimava-se uma narrativa que desencadeava mais lembranças, mais exemplos, e até mesmo piadas e risos atestando o modo como a beleza física é vista no cotidiano do trabalho bancário. Assim, gradativamente, as falas, primeiramente pronunciadas no sentido de que a beleza física nada revelava no trabalho bancário, foram se anulando ao ceder espaço a falas que contavam as experiências vividas condizentes com a rentabilização da beleza física.

A condução dos grupos focais visava propiciar interação entre os participantes de modo que todos tecessem livremente suas opiniões e considerações e, não raro, observou-se certa inquietação e curiosidade por parte dos participantes no sentido de buscar, em conversas paralelas, descobrir a respeito de quem se falava, ou o desencadear de risos incontidos frente a determinados comentários, revelando que o assunto é mobilizador.

A análise dos resultados seguiu orientações de Minayo (2001) para categorização, inferência, descrição e interpretação da seguinte maneira: decomposição do material em unidades de sentido; distribuição das unidades em categorias; descrição das categorias; inferências dos resultados; por fim, interpretação dos resultados priorizando o entendimento qualitativo da realidade social à luz da literatura pertinente, em especial dos estudos de Bauman (2007); Deleuze (1998); Gorz (2005); Lazzarato e Negri (2001); Lipovetsky (1983) e Sant'Anna (2001).

Ainda no que diz respeito ao processo de análise que resultou categorias relativas à beleza física no trabalho imaterial bancário, a apresentação dos resultados conterá tanto falas tomadas individualmente, como trechos dos diálogos empreendidos nos respectivos grupos, de modo a melhor exemplificar uma ideia compartilhada pelo conjunto dos participantes.

\section{Apresentação e Análise dos Resultados}

\section{A beleza física e o trabalho imaterial bancário: do politicamente correto a rentabilização}

Embora não se encontre normatizado ou passível de ser encontrado em qualquer tipo de documentação, o padrão de beleza física vigente no trabalho imaterial bancário se faz assimilar e reproduzir. "A empresa privilegia alguns padrões de beleza, é um código de conduta, é um padrão do banco" (M, GF 8, p. 2). "A O. vai para a linha de frente, porque é bonita. A C. ... Ah, a C. vai lá pro porão, porque não é tão bonitinha assim" (M, GF 7, p. 7). Falas vagas, relativas ao padrão de beleza física vigente no banco, contrastam com a nitidez das práticas que envolvem a beleza física.

A inexistência de normativos relativos à beleza física vigente no banco possibilita, num primeiro momento, a negação do fenômeno pelos trabalhadores. "Beleza não tem relação com o trabalho" (M, GF 5, p. 1). "Eu acho que o banco não tem muito essa questão. No banco acho que não é esse o fator relevante para o trabalho" (H, GF 10, p.1).

Da negação, "eu acho que ela [a beleza física] não influencia em absolutamente nada [no trabalho bancário] (...)" (M, GF 1, p. 1), à afirmação "fulaninho bagulhou, eu já falei também" (M, GF 1, p.29), proferidas pelo mesmo sujeito em distintos momentos, coloca-se em perspectiva, portanto, a migração do politicamente correto à rentabilização que perpassa a discussão da beleza física no trabalho imaterial bancário.

Da ordem do politicamente correto, a negação não se sustenta. "É difícil à gente admitir que a beleza física possa ter esse grau de relevância" (M, GF 1, p. 8). "O que 
se cobra é isso, que a pessoa tem de estar naquele padrão, que geralmente é pessoa alta, magra, que veste bem aquela roupa" (H, GF 7, p. 3). "Não se enganem, e não pensem vocês que não existem estas coisas no banco, porque existe e é forte, é grande, e o assédio é gigante [...] e, inclusive, a gente sabe de muitas histórias que ocorrem lá dentro" (M, GF 7, p. 8).

As categorias de análise - beleza física como investimento na carreira, como instrumento da gestão, como definidora da visibilidade/invisibilidade dos corpos, e como fonte de sofrimento, contemplam a percepção da beleza física como atributo intrínseco ao trabalho imaterial bancário, conforme se verá a seguir.

\section{A beleza física como investimento na carreira} Convictos de que "a gente pode melhorar um pouco, se cuidar, mas tem limites, tu podes fazer muito investimento em dinheiro em beleza" (H, GF 1, p. 3), e de que "é bem isso que estamos falando, da apresentação que tu estás vendendo, do teu produto" (M, GF 5, p. 14), os sujeitos buscam se ajustar aos padrões associando investimento em beleza física com investimento na carreira.

Maquiagem, manicure, chapinha, ginástica, dieta, aplicação de botox e colocação de silicone, entre outros procedimentos disponíveis no mercado de embelezamento, possibilitam crer que "se você fizer, por ser bonita, vai cair nas graças do chefe, e você vai ser promovida sim" (M, GF 7, p. 8), "tem que chegar ao ponto que o padrão estético aceitável possibilite que as pessoas ascendam ou tenham alguma outra possibilidade no banco" (H, GF 12, p. 3).

$\mathrm{Na}$ esteira do controle-estimulação (Mansano, 2009), "as pessoas se cuidam, fazem ginástica, colocam botox" (M, GF 12, p. 8). Trata-se, portanto, de um investimento que envolve dinheiro, tempo e submissão do corpo evidenciado na esfera da gestão de si. "É como a pessoa se arruma, a postura, tem que ser vaidoso - não ao extremo - mas também tem que ser" (H, GF 1, p. 3).
Se à adequação aos padrões de beleza física vigentes associa-se "sempre as bonitinhas, magrinhas, corpinho bonitinho e coisa e tal" (M, GF 7, p. 6), conforme salientara Sant'Anna (2001) referindo-se à magreza e à juventude, também os procedimentos de embelezamento a eles relacionados são vistos como investimento na carreira. Tais investimentos se referem a intervenções mais ou menos invasivas ao corpo, com maior ou menor dispêndio de dinheiro, e distinto tempo de evidência de resultado. Cabe ressaltar, entretanto, que os investimentos que anunciam resultados em curto prazo são os mais requisitados. Para tanto, direcionar o uso do dinheiro e utilizar o tempo de férias para o embelezamento físico, são práticas usuais entre os bancários.

Constatou-se que o investimento em embelezamento físico como investimento na carreira está atrelado à percepção da presença/ ausência de beleza física em relação ao padrão bancário e, independentemente do gênero, da geração e do poder aquisitivo dos indivíduos para se manifestar. Desse modo, o embelezamento físico vai desde o fato de que "tu te obrigas a ir de terninho, a ir com maquiagem, aquela coisa para tu disfarçares um pouco a idade" (M, GF 1, p.24), até a "cirurgia plástica, que atalha o tempo, você tem que se preparar, tem que fazer o padrão, né?" (H, GF 11, p. 8). Homens e mulheres reforçam tal constatação em si e nos demais indivíduos. "Bons cuidados com a unha, cabelo, enfim, vestimenta é o mínimo, hoje com os contatos, tu tens se cuidado um pouco mais" (H, GF 8, p. 1). "Uma coisa que reforça isso é observar a grande incidência de cirurgias plásticas, ou de reparação, em ajustar coisas que se considere que não estão adequadas em questões de beleza" (H, GF 11, p. 6). "Eu vejo o pessoal da antiga, mulheres fazendo plástica no rosto" (H, GF 6, p. 2). "Eu tenho notado no banco, há muito tempo, é que os homens estão tendo mais cuidado, as mulheres estão tendo mais cuidado," (M, GF 6, p. 9). "As minhas colegas, quando tem um grupo de mulheres, estão sempre falando sobre plástica, sobre regime, sobre estética, silicone" (M, GF 12, p. 12). 
A fim de acrescentar ao corpo algo compreendido como falta, ou retirar o que no corpo não é desejado (Sant'anna, 2001), "ondas" (M, GF 1, p. 32) de artifícios relativos ao embelezamento físico como investimento na carreira são compartilhadas no cotidiano do trabalho, conforme atesta a sequência de diálogo a seguir:

— "Ração humana, cada um tem o seu pote de ração humana na mesa. Chá branco; depois chá vermelho. Aí uma aquece a água e fica todo mundo com a sua xícara. 'Toma depois do almoço que é bom, não sente fome'. Ou então assim: 'eu tenho uma nutricionista nova'. 'Ah, então me dá o site dela'" (M, GF 1, p. 32).

— "Medicina ortomolecular agora" $(\mathrm{H}$, GF 1, p. 32).

- "É, aí se faz as dietas, é meio que uma coisa colaborativa, aí todo mundo quer tentar emagrecer" (M, GF 1, p. 32).

Para além de uma conversa qualquer, tecida em reunião informal no momento do cafezinho, o diálogo transcrito revela claramente o objetivo de fazer o investimento em beleza física equivaler a investimento na carreira. Afinal de contas, se perguntam "quem de nós já não fez dieta em algum momento, o tempo todo, para permanecer apto?" (M, GF 2 , p. 18). E se respondem "eu conheci uma executiva no banco, como vou dizer, ela se transfigurava de executiva, roupa e tudo, ela fez todas as plásticas, botox, silicone, tudo" (M, GF 10, p.7).

Como resultado do investimento, "em resumo, o mais bonito ganha mais dinheiro do que quem é mais feio" (H, GF 1, p. 15). "A beleza abre uma porta e - para o que não é tão belo, para o feio - esse tem de provar que tem conteúdo para conseguir abrir aquela porta que para o belo se abre mais facilmente" (M, GF 2, p. 9). Portanto, os investimentos são considerados justificáveis a partir da compreensão de que poderão respaldar ganhos futuros, vindo a legitimar o uso da beleza física como instrumento da gestão.
A beleza física como instrumento da gestão gerencialista

A ausência de beleza física não é impeditiva do ingresso no banco via concurso público, o que é considerado uma desvantagem aos olhos da gestão gerencialista (Gaulejac, 2007), compensada pela contratação de estagiários. "Para contratar estagiárias meninas, normalmente para a recepção, são meninas bonitas, jovens, branca, loirinha" (M, GF 9, p. 3). No que diz respeito à seleção interna para preenchimento de vagas, o critério da beleza física se mostra mais evidente, cabendo ao gestor optar por aqueles em conformidade com o padrão de beleza física vigente no banco. "Eu, quando vou fazer uma seleção na área comercial que envolve gente, envolve pessoas, eu tenho de considerar a beleza física $\operatorname{sim}^{\prime \prime}(\mathrm{H}, \mathrm{GF} 12$, p. 5). "Não interessa muito qual é a tua capacidade, quando chega naquela etapa da seleção, se tu és bonito, se veste bem, se tu estás perfumado, aí então, tu estás selecionado." (H, GF 8, p. 4). "O gerente encontra uma guriazinha bonitinha, e levanta ela, isso é normal. Só que não é instituído, né? Vem por baixo dos panos" (H, GF 1,p. 8).

Na tomada de decisão entre dois candidatos com mesmas competências técnicas, a escolha recai sobre aquele que, presumidamente, é mais bonito. Argumentos tidos como fonte de rentabilização como maiores possibilidades de agradar a clientela e fechar negócio mostram-se infalíveis à seleção dos mais bonitos. "Quando vamos escolher alguém que vai lidar com o público, cuidamos para que não tenha traços que fujam muito daquilo que é o padrão de beleza, porque vai que não consiga fechar um negócio?" (M, GF 1, p. 9).

O raciocínio que conduz à seleção de candidatos belos justifica-se sob a ótica de uma clientela que preferiria ser atendida por aqueles em conformidade com o padrão de beleza física vigente no banco. "É muito comum o cliente, quando vai falar com a gerência uma coisinha simplesinha, ele vai procurar a funcionária, o funcionário bonitinho" $(\mathrm{H}, \mathrm{GF}$ 9, p. 12). "Realmente, ela não era uma pessoa bonita (...) e o cliente se ofendeu com isso, 
insinuando que o banco tinha que colocar outra pessoa ali, ou colocar ela em um cargo que não aparecesse" (M, GF 1, p. 27). Os critérios de seleção relativos à beleza física referem-se, inclusive, à idade dos sujeitos e ao peso dos corpos, possibilitando a relação beleza física com juventude e leveza dos corpos, conforme aponta a literatura (Sant'Anna, 2001; Couto, 2007) “Um superintendente, que passou a administrar aquela agência, inclusive, pessoalmente disse: 'acima de 40 anos, não quero na agência'" (M, GF 3, p. 7). "Reconheço que tive um certo preconceito, pois a pessoa é gorda, mas claro que escolho outra que não é, e vou perder um bom funcionário. É uma realidade" (M, GF 12, p. 4). "Eu sou um pouco mais cruel, se tu tiveres uma pessoa fora dos padrões, mesmo que ela seja mais competente, às vezes tu vais escolher a outra" (H, GF 12, p 4).

Embora não normatizados, tais critérios são amplamente observados na gestão gerencialista do trabalho bancário. Decorre disso que os próprios sujeitos, na perspectiva da gestão de si, que os impele à autoavaliação constante, também se furtam de se apresentar como possíveis candidatos aos processos seletivos internos do banco, uma vez que já internalizaram qual é o padrão de beleza física vigente. O diálogo a seguir foi travado entre um selecionador e um não selecionado de um mesmo processo seletivo. O selecionador ora se expressa na primeira pessoa do singular, ora no impessoal; e o selecionado ora se vê como capaz, ora como incapaz, o que permite, inclusive, inferir a vivência de possíveis dilemas em que o sujeito vê-se entre aquilo que ele acredita e a necessidade de adesão ao projeto organizacional. Tais dilemas tornam-se evidentes nas falas a seguir: "foram lá às mulheres e [falaram] 'tira ela'. O que eu faço? Se eu não tiro, não é porque é boa funcionária, é porque estou defendendo ela. Se ele defender uma mulher bonita 'ah é só porque é bonita'” (H, GF 3, p. 26).

- "Eu sou uma pessoa que, para a área comercial, sei que não sirvo, não que não sirvo, eu já até tentei, eu sou mais operacional. Então, tudo que foi concurso para gerente de negócios, eu nem fui, porque não era o meu perfil.
(...) eu já fui bem mais gorda, continuo meio gordinha (...), então certas coisas eu sei que vão fazer diferença na hora da seleção, então nem tento" $(M, G$ F 12 , p. 15).

- "A P. [referindo-se ao sujeito da fala acima] participou do processo de seleção (...) eu fiz parte da banca que selecionou (...). Eu posso falar disso, porque ela sabe (...) optou-se pelas meninas mais jovens" (H, GF 12, p. 16).

_ "Mais jovens" (M, GF 12, p.16).

— "(...) O banco faz uma pressão para pegarmos uma pessoa mais jovem, com mais tempo para se aposentar" $(\mathrm{H}$, GF 12, p. 16).

O padrão de beleza física vigente no banco também se faz valer nos processos destinados à avaliação de desempenho dos funcionários. "Teve a situação de uma colega que, por ser gordinha, naquelas avaliações que são feitas anualmente, ele deu três notas ruins, em função de ela ser gorda e de não fazer nada para mudar" (M, GF 11, p. 22). Assim, aqueles considerados fora do padrão de beleza física e não empenhados em alcançá-la, além de serem preteridos nas seleções internas são desqualificados nas avaliações de desempenho que oficialmente não contém um item relativo à beleza física.

A fim de contribuir para que o padrão vigente seja alcançado, o banco oferece programas que incluem palestras preferencialmente com cardiologistas, dermatologistas e cirurgiões plásticos, ginástica laboral e campanhas relativas a atividades físicas. "Teve uma palestra sobre cirurgias plásticas, específica para as mulheres, acho que foi na semana das mulheres" (M, GF 12, p. 12). "Tinha profissionais em todas as agências que mediam, para com dados estatísticos incentivar a pessoa a fazer uma atividade física" (H, GF 3, p. 22). "E até surgiu de fazer uma campanha, porque tinha um pessoal mais cheinho, para fazer tipo um prêmio para quem conseguisse perder mais peso" (M, GF 3, p. 22).

Apesar das críticas tecidas a partir da percepção de que "se sobe muito mais rápido do 
que se deveria, e se está queimando talentos dentro do banco em função da idade" $(\mathrm{H}$, GF 9, p. 6), ainda assim a beleza física é determinante da visibilidade/invisibilidade dos corpos em prol da rentabilização.

\section{A beleza física como definidora de visibilidade e invisibilidade}

Observou-se no discurso dos sujeitos o que é apontado por Lipovetsky (1983), que cabe a cada indivíduo a gestão da própria imagem e a capacidade individual de autocontrole. Enfeite e chamariz compreendidos como derivados da presença de beleza física são qualificadores da visibilidade que assumem os corpos alocados na vitrine. Desconfiança e rejeição, como derivados da ausência de beleza física, são qualificadores da invisibilidade que assumem os corpos escondidos "no porão" (M, GF 7, p. 7). A fim de engrossar a fileira dos melhor posicionados na estrutura e no espaço organizacional, na perspectiva da gestão de si (Gaulejac, 2007) os bancários devem estar motivados "para acordar, se arrumar, fazer parte, porque aquilo faz parte da vida" (M, GF 10, p. 3).

Requisitado a reproduzir a imagem institucional no trabalho imaterial bancário (Grisci, 2008), ao gestor de si é evidente que "nós, como profissionais, temos de saber representar a nossa instituição. Se a gente é relaxado, as pessoas vão achar: 'aquele lá é um banco relaxado'" (H, GF 2, p. 19); “É complicado tu trabalhares com uma pessoa que está descabelada e tal, parece que tu não está valorizando o teu trabalho, a tua empresa, a tua vida, não estás te valorizando" (M, GF 8, p. 3). É assim que tornam aceitável que os mais bonitos, apresentáveis, elegantes e afáveis aos olhos dos outros merecem lugar de destaque na vitrine da visibilidade.

Com o objetivo de se fazer notar e atrair, a beleza física é notada em uma "linha de frente selecionada a dedo" (M, GF 4, M, p. 14), de modo que "você olha a recepcionista (...) no atendimento da entrada. São mulheres bonitas, é enfeite" (H, GF 4, p.2)". Cabe ressaltar que para isso "cuidamos para que não tenham traços que fujam muito daquilo que é o padrão de beleza, porque vai que não consiga fechar um negócio" ( $M$, GF 1, p. 9), o que revela o preconceito que tão firmemente tentaram negar no início das discussões.

A visibilidade/invisibilidade dos corpos se relaciona ao preconceito no que diz respeito à presença/ausência da beleza física tanto por parte dos bancários quanto da clientela. Vale lembrar que o preconceito definidor da alocação dos sujeitos nos espaços organizacionais atinge a todos. O público interno do banco considera que "se ele é um cara bem apessoado, ele passa uma credibilidade" $(\mathrm{H}, \mathrm{GF}$ 11, p. 13), e a clientela se julga no direito de se queixar conforme relatado: "Isso é um absurdo, deixar aquelas gurias trabalharem daquele jeito e ainda se fossem bonitas, mas com aquela barriguinha'" (M, GF 2, p. 13). Ou ainda: "uma mulher trabalhando lá, linda, maravilhosa, ela fica inadequada" (M, GF 7, p. 10).

A invisibilidade dos corpos repercute no telemarketing. O telemarketing é descrito e utilizado para atestar que a beleza física não é fator relevante para o trabalho imaterial bancário. "As pessoas tem uma aceitação e, se tratando de Call Center, a beleza não interessa absolutamente nada. Lá têm pessoas obesas, diversos negros, todos os tipos, pessoas estranhas, muito feias" (M, GF 11, p. 23). É necessário, entretanto, considerar que no telemarketing se configura a retaguarda do trabalho bancário não expondo os corpos ao olhar da clientela. "A pessoa lá tem de poder ouvir e falar, porque lá é só isso que elas usam" (M, GF 11, p. 23). "Eles atendem, são robôs, 'papapapa', totalmente doutrinadin$\operatorname{hos}^{\prime \prime}(M$, GF 3, p. 11).

Em contrapartida, a agência central, com maior demanda de clientela, contrasta com o telemarketing. "Na agência central é desfile de mulherada bonita, na verdade, não tem uma menina que tu olhes e diga não, essa não" (M, GF 2, p. 10). A visibilidade dos corpos em decorrência de sua beleza, considerada fonte de rentabilidade e competitividade para o banco, não se mantém com a passagem do tempo. O que não é vivenciado sem sofrimento. "Quando eles atingirem o ápice serão promovidos a Operador de 
Negócios, e é ali que termina. Eles vão ficar o resto da vida na primeira mesa? Na primeira mesa não... até que a beleza deles acabe" (M, GF 7, p. 11).

Ausência e presença de beleza física como fonte de sofrimento psíquico no trabalho imaterial bancário

Seriam preconceitos e sofrimento psíquico consequências da presença/ausência da beleza física no trabalho imaterial bancário? O questionamento aponta para o disciplinamento do corpo em busca do padrão da beleza física vigente como um salvo-conduto na corrida sem fim que não necessariamente resulta o pódio (Sant'Anna, 2001).

Dispositivos de controle-estimulação (Mansano, 2009) atingem a todos, evidenciando que não basta estar no padrão de beleza física, é necessário nele permanecer eternamente para fazer jus à alocação nos postos de visibilidade, o que se mostra um paradoxo frente ao preconceito de que a beleza física é exclusividade da juventude. Independentemente do paradoxo, mostrar-se em constante sacrifício em busca do padrão de beleza física vigente é visto com bons olhos, enquanto o contrário serve para rotular as pessoas como desleixadas e irresponsáveis. "As pessoas valorizam o esforço, quando a pessoa tem um problema de peso e tal: 'pô, está se esforçando'" (H, GF 1, p. 28). "E a gente fala, né? Como uma pessoa nessa posição não se cuida?" (H, GF 8, p. 1). Visto como uma responsabilidade individual, dependente apenas do desejo e da disposição para fazer uso dos dispositivos de controle-estimulação, o padrão de beleza física vigente apresenta-se como aceitável e é anunciado como algo que está ao alcance de todos.

O preconceito não se associa exclusivamente à ausência de beleza física, associa-se também, à presença de beleza física assim questionada: "se é bonitona e aumentou o cargo, ela deu para alguém, ainda está associado a isso, se uma pessoa bonita é valorizada e leva uma promoção, a primeira coisa que perguntam é: 'para quem ela deu'?" (M, GF 2, p. 4). Tal questionamento é confirmado pelo seguinte relato: "pra quem é efetivamente bonita dentro do banco é um incômodo, pois onde você passa todos ficam olhando". (M, GF 7,p. 8).

O preconceito se mostra fonte de sofrimento para aqueles que não correspondem ao padrão e para os que o excedem. "Uma colega por ela ser gordinha, já gera um preconceito das pessoas no tratar com ela, e conversas paralelas não são muito favoráveis à colega. Existe todo um preconceito em cima do trabalho dela, só pela aparência dela, e a competência vai ficar sempre em segundo plano." (H, GF 10, p.2). "Eu escutava bastante lá: 'ah, mas ela é bonita e inteligente também' como se eu tivesse que ser bonita e burra" (M, GF 1, p. 17).

O sofrimento gera dilemas que alcançam de forma específica os gestores. Ao mesmo tempo em que se veem compelidos a selecionar conforme o padrão de beleza física vigente no banco, são julgados por isso. "E sabe o que vai acontecer no caso da estagiária? Vão achar que tu estás protegendo ela" (H, GF 3, p. 19).

A fim de minimizar o mal-estar que toma aqueles fora do padrão, a exigência de emagrecimento muitas vezes é atrelada à promessa da saúde: "eu escuto diariamente, as pessoas falam que seria saudável eu emagrecer por causa da gordura. Ninguém está preocupado, assim com a questão estética, ao menos falam da questão do saudável" (H, GF 12, p.11). A valorização da magreza, juventude e agilidade que se concretiza na visibilidade dos corpos, se torna moeda de troca. A fim de amenizar o sofrimento advindo dos preconceitos, por vezes os sujeitos se impõe ainda mais sofrimento advindo dos procedimentos de embelezamento.

A submissão corriqueira a procedimentos que visam adequar o indivíduo ao padrão de beleza física vigente nem sempre é garantia de minimização do sofrimento, como evidencia a sequência de diálogo que segue.

— "Alguns colegas fizeram redução de estômago, uns engordaram de novo, e outros emagreceram tanto que... também rola discriminação ( $M$, GF 1, p. 33); 
- É verdade, eu enxerguei uma dessas em um colega que trabalhou comigo, que fez a cirurgia, as pessoas olhavam meio estranho (...) (H, GF 1, p.33);

- Acho que até tem certa rejeição, assim, parece que tem alguma coisa (M, GF 1, p. 33);

- Parece que está doente" (H, GF 1, p. 33).

Ao certo, o sofrimento psíquico advém da naturalização dos padrões de beleza física vigentes no banco que atinge a todos, independentemente da beleza que possuem, da idade, da competência, do lugar que ocupam na estrutura organizacional.

Se a pessoa for bonita demais, tu vais olhar para ela e imaginar que ela tem algum defeito. Se ela for feia demais dentro dos padrões, e embora eu ache que é o conjunto o importante, ela também não será [reconhecida]. Se tiver idade demais ela também está fora, se ela tiver de menos também. Então, acho que a gente está sofrendo para ficar no meio (M, GF 1, p. 27).

Para fazer frente ao sofrimento psíquico, de modo individual ou coletivo, a moeda de troca é ininterruptamente avistada. Para tanto, os sujeitos atuam de forma colaborativa ao compartilharem chás, receitas, indicações de médicos, nutricionistas, esteticistas e academias. Compartilham também a justificativa da busca pela beleza física como qualidade de vida; e um modo de destacar o aspecto revigorado que omite possíveis sofrimentos relativos a procedimentos de embelezamento. Nesse sentido, observações de que as férias fizeram muito bem ao visual do sujeito desconsideram que ele as utilizou como investimento na carreira. Mais do que tudo, compartilham a ideia de que da beleza física resultará a visibilidade dos corpos e os afastará do 'porão' da invisibilidade.

\section{Considerações Finais}

O presente estudo alcançou o objetivo de verificar e analisar como a beleza física é vista, e como sua presença/ausência afeta os trabalhadores no cotidiano do trabalho bancário; fez notar a passagem de um discurso politicamente correto à rentabilização dos corpos. Algo que se vê condizente com as práticas da gestão gerencialista (Gaulejac, 2007), ao visar à adesão voluntária à sanção disciplinar, à mobilização de si, à obrigatoriedade, à incitação à imposição. Em que pesem as políticas públicas de inclusão e a disseminação das melhores práticas de gestão, e sua associação à saúde, a beleza física apresenta-se como um dos indicadores da posição dos sujeitos na estrutura organizacional. Tanto sua ausência quanto presença pode acarretar sofrimento psíquico.

Os achados relativos ao contexto do trabalho imaterial bancário encontram respaldo na literatura pertinente (Bauman, 2007; Deleuze, 1998; Gorz, 2005; Lazzarato \& Negri, 2001; Lipovetsky, 1983; Mansano, 2009; Sant'Anna, 2001), que aponta o controle-estimulação, a responsabilização pela conquista e manutenção da beleza física e sua consequente naturalização. Permitem compreender a beleza física como investimento na carreira, instrumento da gestão gerencialista, definidora da visibilidade/invisibilidade dos corpos, e fonte de sofrimento, num conjunto de elementos que indica como os corpos vêm sendo produzidos a fim de atender às demandas do trabalho imaterial. Nesse sentido, a gestão gerencialista se faz notar ao tornar a beleza física rentável e fonte de competitividade entre as empresas. Suas consequências humanas como rejeição, incitação à adesão, impedimentos à ascensão na carreira e sofrimento carecem de divulgação, embora componham o conjunto de elementos relativos à produção de estilos de vida ou modos de existência (Deleuze, 1998) na sociedade líquido-moderna (Bauman, 2007).

Os resultados apresentados indicam a relação entre beleza física e trabalho imaterial e sugerem-na como um campo propício à continuidade de estudos relativos à temática do trabalho, da subjetividade e da gestão. Uma vez que o discurso politicamente correto e naturalizado tende a mascarar 
práticas que podem resultar impedimentos e consequentes sofrimentos aos sujeitos, para futuras pesquisas sugere-se indagar: estariam o discurso politicamente correto e a rentabilização da beleza física também presentes em outros contextos de trabalho? Que relações guardariam com as práticas condizentes com o assédio moral? Que repercussões apontariam no que diz respeito à qualidade de vida? Tais desdobramentos da pesquisa poderão igualmente ser desenvolvidos com a metodologia qualitativa que enfatiza o discurso dos sujeitos e a produção de subjetividade. 


\section{Carmem Lígia lochins Grisci}

Doutora em Psicologia pela Pontifícia Universidade Católica do Rio Grande do Sul, Porto Alegre - RS. Brasil. Docente da Escola de Administração da Universidade Federal do Rio Grande do Sul, Pesquisadora CNPq - 1D.

E-mail: carmem.grisci@ufrgs.br

\section{Estéfani Sandmann de Deus}

Doutoranda em Administração pela Universidade Federal do Rio grande do Sul, Porto Alegre - RS. Brasil.

E-mail: estefanideus@gmail.com

\section{Sabrina Rech}

Mestranda em Administração pela Universidade Federal do Rio Grande do Sul, Porto Alegre - RS. Brasil.

E-mail: sabrinarech@yahoo.com.br

\section{Maura Ferreira Rodrigues}

Mestranda em Administração pela Universidade Federal do Rio Grande do Sul, Porto Alegre - RS. Brasil.

E-mail: mauraferrodriguez@gmail.com

\section{Pedro Henrique de Gois}

Doutorando em Administração pela Universidade Federal do Rio Grande do Sul, Porto Alegre - RS. Brasil.

E-mail: pedrodgois@gmail.com

\section{Endereço para envio de correspondência:}

Escola de Administração - Rua Washington Luiz, 855 - Centro. CEP: 90010-460. Porto Alegre - RS. Brasil.Recebido 09/12/2013, Aprovado 30/07/2014. 


\section{Referências}

Associação Brasileira da Indústria de Higiene Pessoal, Perfumaria e Cosméticos (ABIHPEC). (2013). Valor Econômico: Indústria de higiene e beleza deve crescer $12 \%$. Recuperado em Disponível em 27 de outubro de 2013, de http://www.abihpec.org.br/2012/09/valoreconomico-industria-de-higiene-e-belezadeve-crescer-12/

Backes, D. S., Colomé, J. S., Erdmann, R. H., \& Lunardi, V. L. (2011). Grupo focal como técnica de análise e coleta de dados em pesquisas qualitativas. Mundo da Saúde, 35(4), 438-442.

Bauman, Z. (2007). Vida líquida. Rio de Janeiro: Jorge Zahar.

Couto, E. (2007). Uma estética para corpos mutantes. In: COUTO, E. e GOELLENER, S. (Orgs.) Corpos mutantes: ensaios sobre novas (d) eficiências corporais. Porto Alegre, RS: Ed. da UFRGS.

Deleuze, G. (1998). Conversações : 1972-1990. Rio de Janeiro, RJ: Editora 34.

Faria, J. H., \& Meneghetti, F. K. (2007). O sequestro da subjetividade e as novas formas de controle psicológico no trabalho. In J. H. Faria (Org.), Análise crítica das teorias e práticas organizacionais (pp. 45-67). São Paulo, SP: Atlas.

Foucault, M. (1996). Vigiar e punir: Nascimento da prisão (13a ed). Petrópolis: Vozes.

G1 (2013). Candidatos a vagas de emprego em Porto Alegre ganham trato no visual. Recuperado em 7 de novembro de 2014, de http://g1.globo.com/rs/rio-grande-dosul/noticia/2013/10/candidatos-vagas-deemprego-em-porto-alegre-ganham-trato-novisual.html

Gaulejac, V. (2007). Gestão como doença social: Ideologia, poder gerencialista e fragmentação social. São Paulo, SP: Idéias e Letras.

Goldenberg, M. (2005). Gênero e corpo na cultura brasileira. Psicologia Clínica, $17(2), 65-80$.

Gorz, A. (2005). O imaterial: Conhecimento, valor e capital. São Paulo, SP: Annablume.
Grisci, C. L. I. (2008). Trabalho imaterial, controle rizomático e subjetividade no novo paradigma tecnológico. RAE Eletrônica, 7(1). Recuperado em 27 de outubro de 2013, de http://www. scielo.br/pdf/raeel/v7n1/a05v7n1.pdf

Hamermesh, D. S., \& Biddle, J. E. (1994). Beauty and the labor market. The American Economic Review, 84(5), 1174-1194.

Lazzarato, M., \& Negri, A. (2001). Trabalho imaterial: Formas de vida e produção de subjetividade. Rio de Janeiro, RJ: DP\&A.

Lipovetsky, G. (1983). A era do vazio: Ensaio sobre $o$ individualismo contemporâneo. Lisboa: Relógio D’Água.

Mansano, S.R. V. (2009). Sorria, você está sendo controlado: Resistência e poder na sociedade de controle. São Paulo, RJ: Summus.

Marques, F. (2011). A beleza física: novos estudos mostram que a aparência é fator determinante no sucesso profissional - e que não há nada errado em usá-la. Revista Época, (697), 92-99.

Minayo, M. C. S. (2001). Pesquisa social: Teoria, método e criatividade. Petrópolis, RJ: Vozes.

Miskolci, R. (2006). Corpos elétricos: do assujeitamento à estética da existência. Estudos Feministas, 14(3), 681-993.

Paiva, L. (2007). Corpos amputados e pretetizados: "naturalizando" novas formas de habitar o corpo na contemporaneidade. In E. Couto, S. Goellener (Orgs.), Corpos mutantes: Ensaios sobre novas (d) eficiências corporais. Porto Alegre, RS: Ed. da UFRGS.

Pelbart, P. (2000). A vertigem por um fio: Políticas da subjetividade contemporânea. São Paulo, SP: Iluminuras.

Pelbart, P. (2003). Vida capital: Ensaios de biopolítica. São Paulo, SP: Iluminuras.

Sant'Anna, D. B. (2001). Corpos de passagem: Ensaiossobreasubjetividadecontemporânea. São Paulo, SP: Estação Liberdade.

Torget, S. P. (2013). Pesquisa aponta que médicos descartam realização de cirurgia plástica em cerca de $20 \%$ dos casos. Recuperado em 1 de setembro de 2013, de http://www2. cirurgiaplastica.org.br/midias/pesquisa/ 
Tozzi, E. (2012). Beleza física pode trazer vantagens para a carreira. Revista Exame, (170), 1-2.

Turato, E. R. (2005). Métodos qualitativos e quantitativos na área da saúde: definições, diferenças e seus objetos de pesquisa. Revista de Saúde Pública, 39(3), 507-14.
Veja. (1995, agosto). A vitória sobre o espelho. Revista Veja, 28(1406), 70-79.

Vergara, S. C. (2000). Projetos e relatórios de pesquisa em administração. São Paulo, SP: Atlas. 